\title{
Tourisme et patrimoines immatériels du cheval
}

Introduction

\author{
Sylvine Pickel-Chevalier
}

\section{(2) OpenEdition}

\section{Journals}

Édition électronique

URL : http://journals.openedition.org/tourisme/3014

DOI : 10.4000/tourisme.3014

ISSN : 2492-7503

Éditeur

Éditions touristiques européennes

\section{Référence électronique}

Sylvine Pickel-Chevalier, «Tourisme et patrimoines immatériels du cheval », Mondes du Tourisme [En ligne], 18 | 2020, mis en ligne le 01 mars 2021, consulté le 15 mars 2021. URL : http://

journals.openedition.org/tourisme/3014; DOI : https://doi.org/10.4000/tourisme.3014

Ce document a été généré automatiquement le 15 mars 2021.

\section{c)}

Mondes du tourisme est mis à disposition selon les termes de la licence Creative Commons Attribution - Pas d'Utilisation Commerciale - Pas de Modification 4.0 International. 


\title{
Tourisme et patrimoines immatériels du cheval
}

\author{
Introduction
}

\author{
Sylvine Pickel-Chevalier
}

\section{Le cheval : un objet culturel}

1 Le cheval a accompagné l'évolution des sociétés humaines à travers l'histoire, depuis l'Antiquité en Europe, en Afrique et en Asie, et depuis l'époque moderne sur les continents sud et nord-américains. Cette association s'est illustrée par des pratiques différenciées en fonction des périodes et des populations. Néanmoins, elle a pour particularisme partagé de reposer sur une double identification de cet équidé, défini comme un outil de travail, de chasse, de transport et de guerre (Roche, 2008 ; Lizet, 2020), mais aussi comme un instrument de distinction sociale (Digard, 2007 ; Roche, 2011). Et ce, car le cheval est autant un vecteur d'amélioration de performances permettant à l'homme d'être plus rapide, plus puissant, plus endurant - que d'élévation physique - le cavalier se situant spatialement au-dessus des piétons. Il constitue, de plus, un sujet attisant l'imaginaire des hommes depuis la préhistoire - immortalisé depuis 37000 ans, il est l'animal le plus figuré dans l'art rupestre (Dubois, 2011).

En raison de la pluralité de ses utilisations et représentations, mais aussi de la complexité de la relation à lui, combinant son statut d'objet et de sujet (le cheval étant élevé au rang d'individu par sa portraitisation dans des familles aristocratiques anglaises depuis le XVIII ${ }^{\mathrm{e}}$ siècle, $c f$. Pickel-Chevalier et Grefe, 2015), le cheval fait partie intégrante de l'évolution des sociétés dans leurs rapports au monde. Domestiqué depuis 5000 ans, il a contribué à leurs transformations socioculturelles (Digard, 2007). Stimulant l'invention de matériaux et outils qui ont permis le perfectionnement de son exploitation, il a favorisé l'intensification de l'agriculture, l'expansion des déplacements humains et le développement des échanges culturels et commerciaux. Il a aussi facilité des conquêtes et engendré la métamorphose de modes d'existence - telle que la nomadisation des Indiens des plaines américaines au XIX ${ }^{e}$ siècle (Roe, 1955). 
3 Participant à l'évolution du rapport au temps et à l'espace des sociétés, mais étant aussi transformé génétiquement par elles, afin de mieux répondre à leurs besoins (chevaux trapus pour la traction ou la cavalerie lourde; chevaux affinés pour la cavalerie légère ou l'équitation de cour à la Renaissance; chevaux élancés pour le sport aux XVIII et $\mathrm{xIX}$ siècle, etc.), il est un objet culturel. Nous entendons par objet «une réalité matérielle ou immatérielle construite, stable et isolable, entrant dans des systèmes d'actions mais non dotée d'une intentionnalité » (Ruby et Lévy, 2013, p. 731) et par culture «l'ensemble des productions idéelles disponibles dans une réalité sociale donnée » et "un rapport au monde commun aux membres d'une communauté » (définitions 2 et 5, Lévy, 2013, p. 238). Nous définissons donc un objet culturel comme : une construction sociale susceptible de fonctionner comme producteur et vecteur d'un signifié, reflétant un rapport au monde commun aux membres d'une communauté. Il se caractérise, par ailleurs, par des fonctions médiatrices au sein d'un contexte sociohistorique donné (Diet, 2010).

4 Nous postulons donc que, s'il est un animal, le cheval se définit aussi comme un objet culturel, construit par les sociétés dans leur espace-temps et, en cela, producteur et vecteur de signifiés propres à une communauté. Son identification à un objet culturel nous conduit à reconnaître l'existence de cultures équines, sachant que nous définissons une culture équine comme : un système de pratiques et de représentations liées aux équidés, partagé par une communauté et autour duquel elle s'identifie. Les cultures équines dépassent et intègrent donc la notion de culture équestre, seulement centrée sur l'équitation, pour absorber l'ensemble des rapports au cheval et plus largement aux équidés, en termes d'utilisation (monté, attelé, bâté, enrêné, en liberté) et de représentations.

5 Les cultures équines sont nombreuses et plurielles sur l'ensemble des continents (Adelman et Thompson, 2017), faisant écho à des modes d'existence variés. Elles ont, cependant, pour caractéristiques communes d'avoir été fragilisées par les progrès des sciences et techniques, remettant en question, à partir de la fin du XIX ${ }^{e}$ siècle en Europe de l'Ouest et selon des temporalités différenciées dans le monde, leurs fonctionnements pluriséculaires. Néanmoins, à défaut d'avoir généré la fin du cheval (Raulff, 2018), le $\mathrm{Xx}^{\mathrm{e}}$ siècle a été le témoin de sa recodification sociale, au prisme d'une relation affective - mythe de l'alter ego - associée à un imaginaire largement façonné par les arts populaires enfantins, alors en plein essor (Pickel-Chevalier, 2017). Un imaginaire favorisé par, et éperonnant en retour, le développement de la pratique équestre en tant que loisir (Pickel-Chevalier et Grefe, 2015), au sein de nouvelles communautés de cavaliers plus jeunes et plus féminines, à échelle internationale (Adelman et Knijnik, 2013).

\section{L'invention du patrimoine immatériel et sa relation co- constitutive au tourisme}

6 Cette évolution a, parallèlement, permis au cheval, à l'instar de nombreux objets culturels perdant tout ou partie de leur signification, d'entrer dans une dynamique de patrimonialisation, sans nécessaire rupture de valeurs (Pomian, 1990). Ainsi, la remise en cause des cultures équines traditionnelles dans le monde moderne engendre simultanément la "consciencialisation » d'un sentiment d'identité et la crainte de la perdre, qui sont le plus souvent intrinsèquement liées, dans un rapport construit au 
temps et à l'histoire (Hartog, 2012). En effet, le processus de changement de signifié des objets culturels dans la conscience collective - passant de l'utilitaire au mémoriel permet leur redéfinition en tant que patrimoine (Babelon et Chastel, 1994). Ce dernier est identifié par le Conseil de l'Europe comme :

un ensemble de ressources héritées du passé que des personnes considèrent, pardelà le régime de propriété des biens, comme un reflet et une expression de leurs valeurs, croyances, savoirs et traditions en continuelle évolution. Cela inclut tous les aspects de l'environnement résultant de l'interaction dans le temps entre les personnes et les lieux. (Conseil de l'Europe 2005, article 2) ${ }^{1}$

Or, cet héritage a été élargi, notamment sous les recommandations d'ethnologues français, au patrimoine immatériel, identifié en 2003 par l'Unesco comme :

les pratiques, représentations, expressions, connaissances et savoir-faire - ainsi que les instruments, objets, artefacts et espaces culturels qui leur sont associés - que les communautés, les groupes et, le cas échéant, les individus reconnaissent comme faisant partie de leur patrimoine culturel. Ce patrimoine culturel immatériel, transmis de génération en génération, est recréé en permanence par les communautés et groupes en fonction de leur milieu, de leur interaction avec la nature et de leur histoire, et leur procure un sentiment d'identité et de continuité, contribuant ainsi à promouvoir le respect de la diversité culturelle et la créativité humaine. (Convention pour la sauvegarde du patrimoine culturel immatériel, 2003, article 2) ${ }^{2}$

Le patrimoine immatériel se distingue du patrimoine ethnologique, en se réclamant de "l'idée d'une transmission effective des pratiques dans une démarche qui se veut de développement durable " (Bortolotto, 2011, p. 37). Selon l'anthropologue Jean-Louis Tornator, il constitue ainsi un concept innovant, insistant sur l'implication des acteurs de la patrimonialisation, menant à la notion de « communauté », définie par le Conseil de l'Europe comme les «personnes qui attachent de la valeur à des aspects spécifiques $\mathrm{du}$ patrimoine culturel qu'elles souhaitent, dans le cadre de l'action publique, maintenir et transmettre aux générations futures" (Conseil de l'Europe 2005, article 2) ${ }^{3}$. Chiara Bortolotto s'inscrit aussi dans cette approche, en rappelant que :

la définition insiste en fait sur le rôle des acteurs sociaux (« communautés, groupes et, le cas échéant, individus ») dans la reconnaissance patrimoniale, sur la dimension non seulement historique ( transmis de génération en génération »), mais en même temps évolutive et processuelle de ce patrimoine ( recréé en permanence »), sur sa fonction identitaire pour les acteurs sociaux auxquels ce patrimoine procurerait un "sentiment d'identité", tout en se limitant aux pratiques non discriminatoires et conformes à l'éthique globale émergente. (2011, p. 26)

9 Ce patrimoine immatériel positionne donc la communauté au centre de ses préoccupations, comme agent fondamental de la transmission, mais aussi de la régénération constante, d'une culture vivante, autour de laquelle elle s'identifie. La culture se veut donc dynamique, en intégrant la perpétuelle recréation, spontanée ou institutionnalisée, des traditions (Hobsbawm et Ranger, 2012).

Le tourisme joue un rôle essentiel dans ce processus. Comme le souligne le géographe Olivier Lazzarotti « le patrimoine et le tourisme sont deux phénomènes d'une même dynamique de production mémorielle : ils sont co-constitués » (2011, p. 72). Le tourisme permet, en effet, de promouvoir, mais aussi de réinventer, une partie choisie de son héritage (Picard, 1992), recodifiée comme autant de jalons identitaires culturels, au travers des interactions entre des acteurs endogènes - communauté - et exogènes. Ces derniers comprennent les pouvoirs publics, des entreprises privées, mais aussi les 
touristes, la population locale se réappropriant en partie les projections et imaginaires portés sur elle (Staszak, 2008). L'identité individuelle et collective émane d'une construction sociale intégrant le rapport à l'altérité, au travers d'un double processus d'assimilation/distanciation (Stascak, Debardieux et Pieroni, 2017) et parfois d'interculturation (Pickel, Violier et Parantika, 2018). Tourisme, culture et patrimoine, plus particulièrement immatériel, se nourrissent ainsi réciproquement (Richards, 2000 ; Lazzarotti et Violier, 2007 ; Hitchcock, King et Parnwell, 2010). Cette co-constitution est notamment mise en exergue, comme le rappelle Frédéric Maguet, par le fait que $85 \%$ des patrimoines immatériels inscrits sur le site de l'Unesco concernent des activités qui impliquent l'existence de publics: pratiques artistiques musicales, spectacles de marionnettes, théâtres, carnavals, festivals, etc. (Maguet, 2011, p. 34).

\section{Tourisme et patrimoines immatériels équins : un nouvel objet scientifique}

11 Nous postulons que l'objet culturel cheval est entré, du fait de sa fragilisation dans le monde contemporain, dans une dynamique de patrimonialisation. Le cheval étant fondamentalement associé à des systèmes de pratiques, savoir-faire et représentations, il relève d'un patrimoine à la fois matériel (animal socialement construit; équipements) et immatériel (modes d'existence), autour duquel un groupe s'identifie. De ce fait, l'objet culturel cheval constitue un sujet d'étude stimulant, s'inscrivant dans l'analyse des processus de co-constitution entre tourisme et patrimoine. Il interroge, plus particulièrement :

- la détermination de la communauté se reconnaissant dans ce patrimoine (logique inclusive/ exclusive), questionnant la construction des identités ;

- les relations intrinsèques entre patrimoines matériels et immatériels, s'alimentant réciproquement ;

- la transmission culturelle intergénérationnelle, complexifiée par le changement de profils des pratiquants (ruraux, masculins/urbains, féminins);

- le rôle essentiel du tourisme dans ces procédés, contribuant à la conservation des patrimoines matériels et immatériels entre préservation, adaptation et réinvention.

12 L'objet culturel cheval, en tant que patrimoine de l'humanité, est aussi innovant car il interpelle le rapport à l'animal dans sa complexité, apostrophant notamment l'ethnologie inter-espèces, qui interroge la capacité du chercheur à parler "de » et parler "pour " au prisme de sa cognition. Cette dernière intègre la mouvance des nouvelles sensibilités animalistes, s'opposant parfois violemment à l'identification des cultures traditionnelles entretenant des relations plus utilitaristes au cheval.

Nous proposons de répondre à ces questionnements en étudiant des cultures équines, en tant que patrimoines immatériels adossés aux patrimoines matériels du cheval, dans leur diversité à la fois géographique et socioculturelle. En effet, le rapport aux équidés a donné jour à deux types de société différenciés, identifiés par l'ethnologue Jean-Pierre Digard comme : des sociétés à écuyers - où le cheval et l'équitation sont réservés à une élite sociale devant apprendre des techniques équestres sophistiquées, témoignant de son appartenance aux classes privilégiées - et les peuples cavaliers - où le cheval et l'équitation sont socialement diffusés dans l'ensemble des strates de la population, sans 
distinction de classe, genre ou âge, en utilisant des pratiques équestres simplifiées, essentiellement dévolues au déplacement, la chasse ou le travail (Digard, 2007).

Ce dossier thématique, qui se veut à la fois international (concernant des études de cas répartis dans sept pays) et interdisciplinaire (croisant les regards de géographe, sociologue, anthropologue, ethnologue et gestionnaire) intègre cette dichotomie. La géographe Sylvine Pickel-Chevalier s'intéresse à la continuité de la maîtrise de l'art équestre des sociétés à écuyer en France, en Espagne et au Portugal, en analysant le mode de fonctionnement du Cadre noir de Saumur/IFCE, de la Real Escuela Andaluza del Arte Ecuestre (Jerez) et de la Escola Portuguesa de Arte Equestre (Lisbonne), aujourd'hui largement réinventées au travers de leur mise en tourisme, qui nécessite de profondes mutations socioculturelles et économiques.

15 L'anthropologue Thomas Apchain questionne, à la suite, la capacité d'appropriation d'un patrimoine immatériel équestre classé à l'Unesco en 2011, à savoir l'équitation de tradition française. Son analyse comparative, centrée sur les villes de Saumur, Deauville et Chantilly, capitalisant sur le cheval comme marqueur identitaire, soulève la problématique de la territorialisation, largement orchestrée par des logiques de développement touristique, d'un patrimoine se réclamant pourtant national et à rayonnement universel.

16 Nous quitterons ensuite les enjeux de la perpétuation et de la diffusion de l'art équestre des sociétés à écuyers pour nous intéresser aux évolutions des pratiques de peuples cavaliers, qui existent encore en Europe et dans le monde. Si le cheval ne constitue plus nécessairement le quotidien de l'ensemble de leur population, il demeure un objet culturel populaire, porteur d'un signifié identitaire essentiel pour des communautés villageoises ou de quartiers. Nous interrogeons, dans ce cadre, la capacité du tourisme à favoriser leur renouvellement, dans la société contemporaine qui les fragilise, voire les conteste.

17 Ainsi, l'anthropologue Letizia Bindi analyse la complexité de la situation des fêtes populaires italiennes autour de compétitions rituelles équestres, tel que le Palio de Sienne. Condamnés par les mouvements animalistes, ces évènements, qui retranscrivent un rapport à l'animal traditionnel utilitaire et relativement brutal, constituent des objets culturels au cœur de polémiques, interpelant la notion même de culture, plaidée par la communauté locale, mais désavouée à l'échelle nationale. La mise en tourisme de ces compétitions équestres, conférant un rayonnement international aux cités qui les perpétuent, semble pouvoir leur assurer un avenir, qui nécessite néanmoins des changements socioculturels, parfois difficiles à assimiler par la collectivité.

Ce rapport ambigu du tourisme aux patrimoines immatériels du cheval, favorisant leur perpétuation au prix de transformations profondes, caractérise aussi certains villages brésiliens. La sociologue Miriam Adelman analyse plus particulièrement le cas de São Luiz do Purunã, marqué par l'émergence de nouvelles ruralités, résultant du flux de citadins qui s'y installent et le refaçonnent, au détour de leurs projections et imaginaires. Ces derniers se cristallisent notamment sur le Gaúcho, l'homme de cheval. La population locale s'efforce d'intégrer cette nouvelle culture hybride, par un engagement croissant dans le développement touristique de leur village. Toutefois, cette mise en tourisme repose sur des interactions complexes entre communauté endogène et agents exogènes, générant des réorganisations sociales, qui s'illustrent parfois par le renforcement des problèmes d'inégalité, voire de marginalisation. 
19 Nous nous intéresserons, par ailleurs, à la patrimonialisation du tourisme équestre en Islande, où les chevaux sont, dans certaines régions, plus nombreux que les hommes. Guðrún Helgadóttir et Ingibjörg Sigurðardóttir, chercheurs en sciences de gestion, interrogent l'expérience du tourisme domestique à cheval comme mode de perpétuation d'un patrimoine immatériel. En effet, ses pratiquants recherchent à travers elle une reconnexion avec la culture traditionnelle, en partie réinventée, à travers des longues traversées sur les anciens chemins de transhumances, au cœur de milieux naturels arctiques, sur les chevaux islandais. Ils assimilent cette pratique touristique à la conservation d'une culture équine, combinant patrimoine matériel (le cheval) et immatériel (mode de déplacement et d'existence), qui exige néanmoins des adaptations, notamment en termes de logistique et d'accueil d'une population devenue citadine.

Enfin, nous analyserons les limites de la mise en tourisme des patrimoines immatériels du cheval, interrogeant le rapport à l'altérité, au travers de l'étude du jeu de tire-bouc, très populaire en Asie centrale. En analysant plus précisément le bouzkachi afghan pratiqué au Kirghizstan et au Kazakhstan, l'ethnologue Carole Ferret décrypte les difficultés de la touristification d'une pratique culturelle rituelle violente et relativement anarchique. Si elle est essentielle aux communautés locales, elle demeure, en dépit d'une volonté politique gouvernementale, peu encline à entrer dans une dynamique touristique. Cette dernière suppose un processus de normalisation la rendant accessible, compréhensible, mais aussi acceptable aux touristes étrangers, notamment occidentaux, dotés d'une sensibilité animaliste qui les oppose aux relations utilitaristes traditionnelles aux chevaux desdits peuples cavaliers afghans.

21 Ainsi, les articles questionnent, plus particulièrement, le rôle du tourisme dans: l'identification et la réinvention permanente des patrimoines immatériels équins; la détermination de leur communauté, interrogeant la construction des identités dans le rapport à l'altérité ; les processus de diffusion et d'appropriation, au sein de sociétés contemporaines qui parfois s'y opposent; les politiques de conservation, nécessitant des logiques d'adaptation et d'innovation, induisant des restructurations socioéconomiques et culturelles, assimilées ou non par les communautés concernées.

Ce dossier, qui interpelle la notion de culture équine, s'avère novateur par sa thématique, comme par son caractère international et interdisciplinaire, qui permet la mise en exergue de méthodologies de recherche différenciées. Il fait suite au colloque "Cheval et patrimoine", coorganisé le 12 octobre 2019 à Saumur par l'UFR ESTHUA Tourisme et culture de l'Université d'Angers et la Mission française pour la culture équestre, une association notamment destinée à « agir en faveur de la reconnaissance de l'ensemble des patrimoines et des cultures liés au cheval comme éléments importants de la diversité et de la créativité culturelles et à encourager et promouvoir la recherche dans ces domaines $»^{4}$. Les deux institutions sont aussi cofinanceuses du dossier. 


\section{BIBLIOGRAPHIE}

Miriam ADELMAN et Jorge KNIJNIK, Gender and Equestrian Sport, Springer, 2013.

Miriam ADELMAN et Kirilly THOMPSON, Equestrian Cultures in local and global contexts, Springer, 2017.

Jean-Pierre BABELON et André CHASTEL, La notion de patrimoine, Liana-Levi, 1994.

Chiara BORTOLOTTO (dir.), Le patrimoine culturel immatériel. Enjeux d'une nouvelle catégorie, Éditions de la Maison des sciences de l'homme, 2011.

CONSEIL DE L'EUROPE, Convention-cadre du Conseil de l'Europe sur la valeur du patrimoine culturel pour la société, 2005 [https://rm.coe.int/1680083748].

Emmanuel DIET, «L'objet culturel et ses fonctions médiatrices », Connexions, vol. 1, n 93, 2010

[https://www.cairn.info/revue-connexions-2010-1-page-39.htm].

Jean-Pierre DIGARD, Une histoire du cheval, Actes Sud, 2007.

Hélène DuBoIs, Légendaire cheval. Mythes, folklores et traditions, Mens Sana, 2011.

François HARTOG, Régime d'historicité. Présentisme et expériences du temps, Édition du Seuil, 2012.

Eric HOBSBAWM et Terence RANGER, The invention of tradition, Cambridge University Press, 2012.

Michael HITсHсоск, Victor T. KING et Michael PARNwell (dir.), Heritage Tourism in Southeast Asia, Nias Press, 2010.

Olivier LAZZAROTTI, Tourisme et patrimoine, Belin, 2011.

Olivier LAZZAROTTI et Philippe VIOLIER, Tourisme et patrimoine : un moment du monde, Presses universitaires d'Angers, 2007.

Jacques LÉVY, «Culture » dans Jacques LÉVY et Michel LUSSAULT (dir.), Dictionnaire de la géographie et de l'espace des sociétés, Belin, 2013.

Bernadette LIZET, Le cheval dans la vie quotidienne, CNRS éditions, 2020.

Frédéric MAGUET, «L'image des communautés dans l'espace public » dans Chiara BORTOLOTTO (dir.), Le patrimoine culturel immatériel. Enjeux d'une nouvelle catégorie, Éditions de la Maison des sciences de l'homme, 2011.

Michel PICARD, Bali : tourisme culturel et culture touristique, L'Harmattan, 1992.

Sylvine PICKEL-CHEVALIER, « Popular Horse Stories and the Invention of the Contemporary HumanHorse Relationship through an 'Alter Ego' paradigm », Journal of Sports Science, vol. 5, 2017.

Sylvine PICKEL-CHEVALIER, « L'équitation française et sa patrimonialisation dans la société des loisirs ", EspacesTemps.net, 2016 [https://www.espacestemps.net/articles/lequitation-francaiseet-sa-patrimonialisation-dans-la-societe-des-loisirs/].

Sylvine PICKEL-CHEVALIER et Gwenaëlle GREFE, « Le cheval réinventé par la société des loisirs en Occident : une mythologie révolutionnée? $\left(\mathrm{XVIII-XXI}{ }^{\mathrm{e}}\right) »$, Cheval, tourisme et sociétés/Horse, Tourism and Societies, Mondes du tourisme, Hors-série, 2015.

Sylvine PICKEL-CHEVALIER, Philippe VIOLIER et Asep PARANTIKA, « Le tourisme, agent d'interculturation sociospatial ? Le cas des pratiques touristiques littorales indonésiennes à Bali et à Java ", L'Espace géographique, vol. 2, t. 47, 2018. 
Krzysztof POMIAN, « Musée et patrimoine », dans Henri Pierre JEUDY (dir.), Patrimoines en folie, Éditions de la Maison des sciences de l'homme, 1990.

Ulrich RAULFF, Farewell to the Horse, Penguin Book, 2018.

Greg RICHARDS, «Tourism and the World of Culture and Heritage » Tourism Recreation Research, vol. $25, \mathrm{n}^{\circ} 1,2000$.

Daniel RocHE, La culture équestre de l'Occident, XVI-XIX siècle. T1. Le cheval moteur, Fayard, 2008.

Daniel RocHE, La culture équestre de l'Occident, XVI-XIX ${ }^{e}$ siècle. La puissance et la gloire, Fayard, 2011.

Frank Gilbert ROE, The Indian and the Horse, University of Oklahoma Press, 1955.

Christian RUBY et Jacques LÉVY, « Objet », dans Jacques LÉVY et Michel LUSSAUlT (dir.), Dictionnaire de la géographie et de l'espace des sociétés, Belin, 2013.

Jean-François STASZAK, « Qu'est-ce que l'exotisme ? », Le Globe, vol. 148, 2008.

Jean-François STASZAK, Bernard DEBARDIEUX et Rafaël PIERONI, « Frontières, altérité, identité », dans Jean-François STASZAK (dir.), Frontières en tous genres, cloisonnement spatial et constructions identitaires, Presses universitaires de Rennes, 2017.

Jean-Louis tORNATORE, « La difficile politisation du patrimoine ethnologique » Terrain, $\mathrm{n}^{\circ}$ 42, 2004. UNESCO, Convention pour la sauvegarde du patrimoine culturel immatériel, 2003 [https:// ich.unesco.org/fr/convention].

\section{NOTES}

1. Voir : https://rm.coe.int/1680083748

2. Voir : https://ich.unesco.org/fr/convention\#art2

3. Voir : https://rm.coe.int/1680083748

4. Voir : https://www.equitation-francaise.fr/

\section{AUTEUR}

\section{SYLVINE PICKEL-CHEVALIER}

Associate Professor

Research Director in Geography (HDR)

ESTHUA University of Angers

UMR CNRS 6590 Spaces and Societies

Sylvine.chevalier[at]univ-angers.fr 